\title{
Local cutaneous allergy to monocomponent insulin
}

\author{
D. Q. BORSEY* \\ M.R.C.P. (U.K.)
}

\author{
D. N. S. MALONE \\ F.R.C.P.
}

\author{
Milesmark Hospital, Dunfermline KY12 9NR
}

\begin{abstract}
Summary
A case is described of a patient who developed local cutaneous hypersensitivity soon after commencing treatment with monocomponent insulins (MCI). This appears to be the first record of such a case.
\end{abstract}

\section{Introduction}

Monocomponent insulins (MCI) were developed by Schlichtkrull et al. (1972), in Denmark, and have been marketed in the United Kingdom since 1975. A major advantage claimed has been their freedom from antigenicity.

\section{Case report}

A 25-year-old female diabetic was admitted with hypoglycaemia which responded to intravenous dextrose. Previously, she had been well controlled with moderate morning doses of soluble and protamine zinc (PZI) insulins, and gave no history of insulin allergy. She had, however, developed marked lipoatrophy at the injection sites and occasionally suffered from mild eczema. Her sister had bronchial asthma.

Because of the lipoatrophy it was decided to change her treatment to MCI. She was given 20 units Semitard (Novo Industries) and 16 units Actrapid (Novo) in the morning, and 10 units Semitard and 8 units Actrapid in the evening. The first 2 doses of each insulin produced no ill effects but thereafter she developed a painful local reaction at the injection sites. Immediately after subcutaneous injection she experienced intense burning discomfort and, within a few minutes, this was surrounded by an erythematous and pruritic area $5 \mathrm{~cm}$ in diameter which persisted for $20 \mathrm{~min}$. For a further 2 to $3 \mathrm{hr}$, there remained a tender and indurated area $3.5 \mathrm{~cm}$ in diameter. In the hope that this reaction to $\mathrm{MCI}$ was only temporary, treatment was continued. However, the reaction became more marked and, after 4 days, therapy was changed to the Nordisk

Correspondence to: Dr David Q. Borsey, 28 Buckstone Court, Edinburgh EH10 6UL
MCIs, Leo Retard and Leo Neutral. These produced identical local reactions. The patient requested that she should return to her original therapy and she was recommended on PZI and soluble insulin with no further trouble.

Eosinophil count, IgE level and complement profile were normal. Skin tests were performed with the following insulins: (a) Leo Retard 40; (b) Leo Neutral 40; (c) Wellcome Soluble 80; (d) Wellcome PZI 80; (e) Actrapid 80; (f) Semitard 40. Skin prick tests revealed no evidence of immediate hypersensitivity, being negative at $10 \mathrm{~min}$ for all the above preparations. Intradermal tests using $0.01 \mathrm{ml}$ insulin were negative at $6 \mathrm{hr}$ apart from $6 \mathrm{~mm}$ erythema with Semitard. After $12 \mathrm{hr}$ erythema and itchiness were noted with Leo Retard and Semitard, and at $48 \mathrm{hr}$ all tests were negative.

\section{Comment}

The rapid onset of symptoms and signs suggested an immediate Type I hypersensitivity reaction. However, the skin tests were more in keeping with a Type III hypersensitivity resulting from the combination of antigen with circulating antibody. The fact that there occurred a reaction to both of the depot MCIs could be interpreted as indicating hypersensitivity to the carrier rather than to the insulin itself. However, the clinical findings were against this as she was observed repeatedly to react to both the soluble and depot MCIs.

Although the claims that MCIs are virtually nonantigenic (Schlichtkrull et al., 1972; Czyzyk et al., 1974) have been challenged (Yue and Turtle, 1975), it is generally considered that they may benefit patients with insulin hypersensitivity as well as those with lipodystrophy and insulin resistance. Several workers have expressed the view that with $\mathrm{MCI}$ cutaneous allergies are largely abolished and 'will probably no longer be observed' (Teuscher, 1975).

Novo Industries in their promotional literature state that 'localized and generalized cutaneous allergies have not been reported with Novo MCI'. However, a generalized allergic reaction to MCI has 
recently been described in a patient who had repeatedly suffered local cutaneous hypersensitivity reactions to conventional insulins (Leslie, 1977). A review of the English language journals has revealed no case similar to the one reported above.

\section{Acknowledgment}

We thank Dr S. J. Urbaniak, Deputy Director, South-East Scotland Regional Blood Transfusion Service, for performing the skin tests and complement profile.

\section{References}

CzyzyK, A., Lawecki, J., Rogala, H., Miedzinska, E. \& Popik-Hankiewicz, A. (1974) Serum levels of insulinbinding antibodies in diabetic patients treated with monocomponent insulin. Diabetologia, 10, 233.

LESLIE, D. (1977) Generalized allergic reaction to monocomponent insulin. British Medical Journal, 2, 736.

Schlichtkrull, J. Brange, J., Christiansen, Aa.H., Hallund, O., Heding, L.G. \& Jørgensen, K.H. (1972) Clinical aspects of insulin antigenicity. Diabetes. 21 (Suppl. 2), 649.

Teuscher, A. (1975) Der Platz der monokomponentInsuline in der Therapie des Diabetes Mellitus. Schweizerische medizinische Wochenschrift, 105, 485.

Yue, D.K. \& TURTLE, J.R. (1975). Antigenicity of monocomponent pork insulin in diabetic subjects. Diabetes, 24, 625 . 